\title{
Rheological Behaviors and Their Correlation with Printing Performance of Silver Paste for LTCC Tape
}

\author{
Rosidah Alias and Sabrina Mohd Shapee \\ TM Research \& Development Sdn. Bhd., \\ Malaysia
}

\section{Introduction}

Low Temperature Co-fired Ceramic (LTCC) technology has attracted much attention for high frequency applications due to the advantages in preparing 3D circuits within a ceramic block that enables burying of passive elements; resistor, inductor and capacitor (Jantunen et al., 2003). This technology also offers another advantages such as low fabrication cost due to parallel process, utilizing high conducting metal, higher interconnect density, high performance thermal management system, shrinking of circuit dimensions and high level of passive integration (Lin and Jean, 2004; Gao et al., 2010). The LTCC multilayer technology process generally consists of cutting the green tape ceramic into the required dimension, via punching, via filling, screen printing, stacking, lamination and co-firing process. All these steps are important to achieve a good quality of the final structure. Furthermore, LTCC technology requires cofiring process of conductor and ceramic-glass substrate. The co-firing mismatch should be avoided to make sure the resulting product has good appearance. The key point of LTCC technology is the screen printing process of thick-film technology which strongly depends on the optimization of the conductor paste rheological behavior. Besides, the characteristics and the quality of printed conductor lines are greatly affected by some process variables such as screen printing speed, angle and geometry of the squeegee, snapoff and screen mesh parameter including the paste characteristics (Hoornstra et al., 1997; Yin et al., 2008). The performance of the paste depends on the variety of factors including storage, how easily and accurately it can be deposited (printing) and the flow characteristics (rheology) (Nguty and Ekere, 2000). Thick-film paste must maintain good printability throughout the time on the screen and the screen parameters must allow for high throughput and repeatability results (Harper, 2001; Buzby \& Donie, 2008). The successful story of making multilayer substrate is depends on this steps. Consequently, a thorough understanding of the influence of the paste rheological behavior and the combination with other parameters is essential if this objective is to be met.

Generally, the electrical connection between components and layers are given by the conductor paste such as silver, copper, gold, silver-palladium, silver-platinum and etc. Compared to the other conductor materials, silver thick film has been used as the main conductive material for LTCC technology due to their excellent electrical properties, thermal 
conductivity and the lower cost price of conductor material (Wu et al., 2010; Chen et al., 2010). The characteristics of the silver particles strongly affect the paste rheology and subsequently alter the densification of the printed track. Different formulations of the paste are used to produce conductors that basically consists of several major ingredients; (1) the metal powders, which provide the conductive phase; (2) glasses or oxides, which act as a permanent binder and also promote sintering of metal powders during firing and enable binding of the functional film to the substrate; (3) organic vehicle, which disperse the functional and binder components to impart the desired rheological properties to the paste; and (4) a solvent or thinner that establishes the viscosity of the vehicle phase (Taylor et al., 1981; Lin and Wang, 1996; Rane et al., 2004; Sergent, 2007). Such pastes are screen printed in the desired pattern on the substrate, dried and fired at a certain temperatures to form a conducting thick-film with a thickness ranging from 3 to $30 \mu \mathrm{m}$ (Rane et al., 2003).

\subsection{Basic information/thick-film materials}

Thick-film is generally considered to consist of layers of paste deposited onto the substrate. One of the key factors that distinguish thick-film circuit is a method of thick film deposition.

In LTCC process, screen printing is one of the most dominant methods to deposit conductor paste on a substrate. The screen printing of thick film patterns on the LTCC multilayer substrate is employed for thick film systems due to a low-cost and much simpler process to produce a circuit design on substrate compared to other process. The printing process are done only at the place where required and follow the design pattern which are prepared earlier (Vasudivan \& Zhiping, 2010). The printing quality and the fine line printing resolution patterns is necessary in order to achieve high component density and high frequency applications (Dubey, 1975; Kim et al., 2010). Successful transferred pattern onto the substrate depends on the rheology of the paste material. The range of most available for thick-film technology is determined by their capacity to be both printed and fired. Establish thick-film technology is based on three classes of material supplies in the form of printing paste; conductors, resistors and dielectrics. For this report we only concentrate on the conductor paste.

Thick-film circuits are created in thick-film printing patterns in paste which basically composed of organic carrier, glass-frit and active elements such as gold, silver, silver platinum and silver palladium. As mention above, silver paste is the most selected material due to the good conductivity and good characteristics which depends on the functional paste whether precious metal such silver, gold or base metal such $\mathrm{Ni}, \mathrm{Cr}$ and $\mathrm{Al}$. An organic carrier dispersed the binder and functional components to impart the desired rheological properties of the paste while the glass-frit act as permanent binder and help to promote metal powders during sintering and also provide binding between thick-film and the substrate (Hwang et al., 2009; Shiyong et al., 2008). The printing process is known to be controlled by a number of process parameters such as screen mesh parameters, printer setting parameters, environmental conditions and paste parameters (Durairaj et al., 2009b). Some of these parameters are fixed (eg. screen mesh). However the paste parameters generally change during the printing process cycles; before printing process, during printing and after printing process as seen in Fig. 1. So, it also noted that the viscosity is a function of the time. One of the paste parameters is the rheological properties and flow history of the 
paste (Parikh et al., 1991; Burnside et al., 2000). The printing behavior of the paste is characterized by its rheology through the viscosity value.

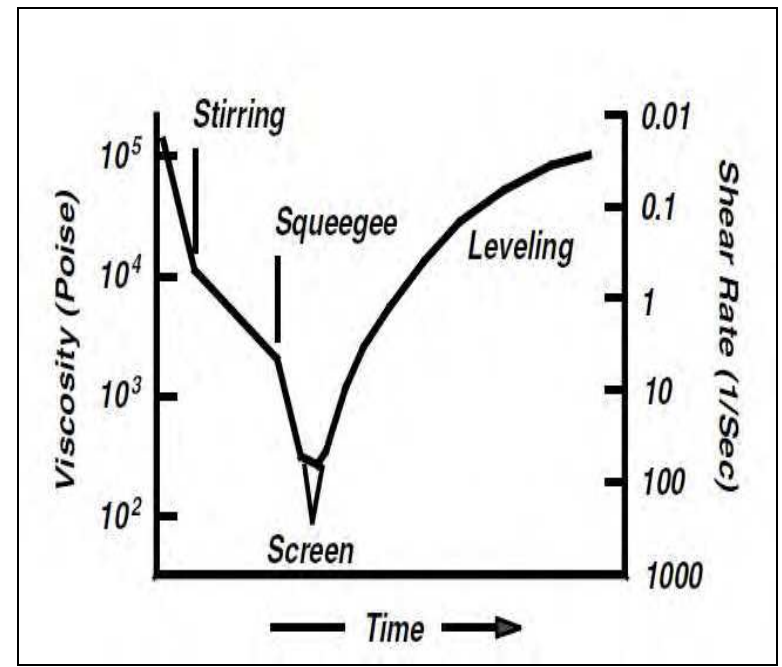

Fig. 1. Variation in the paste viscosity at different stages of the printing cycle (Barlow \& Elshabini, 2007)

The viscosity is the most important rheological characteristics of the conducting paste (Gilleo, 1989). The conducting paste for screen printing process should show the pseudoplastic behavior which displays a decreasing viscosity with an increasing shear rate (Hoornstra et al., 1997). However, to be suitable for screen printing, conducting paste should be somewhat thixotropic in nature. A thixotropic fluid is one in which the shear rate/shear stress ratio is nonlinear. As the shear rate (which translates to the combination of squeegee pressure, velocity, and screen tension) is increased, the paste becomes substantially thinner, causing it to flow more readily.

The optimum operating viscosity of the paste is dependent on the parameters with the screen printing process. The variations in squeegee speed, squeegee to screen angle, squeegee pressure and snap-off distances will affects the quality of the printed film. If the printed lines have a tendency to spread on standing, it is likely that the viscosity of the paste is too low. Chiu, (2003) in his experiment also noted that the paste viscosity is a significant factor to control the line width including the thickness and roughness of the printed pattern. The paste viscosity is too high if the printed films display mesh marking, pinholes or very thin areas covered with paste.

The aim of this work is to modify the viscosity of silver paste in order to get the required thickness and fine line printing of printed material on the substrate. As well known, controlling the properties of resulting conductor thick film paste is not a simple task, so in order to comply with required properties, the conductor paste need to do some adjustment in terms of its viscosity behavior. Viscosity can be lowered (by addition of the solvent) or increased (by addition of a thixotropic nonvolatile vehicle), although the latter will require re-milling of the paste. 
The investigation of rheology of the paste has been studied by several researchers especially for solder paste and conductor material for solar cell applications such as Shiyong et al., (2008), Amalu et al., (2011), Mallik et al., (2009), Durairaj et al., (2004), and Burnside et al., (2000). Their studies reported that the solder paste shows thixotropics behavior, shear thinning and yield stress. Jackson et al., (2002) noted in their paper, a good quality paste will have optimum shear thinning properties allowing flow in mesh aperture, a suitable thixotropic nature for recovery and a non tendency to slump after printing. The paste also should retain its intended printed thickness and continuity. Previous studies by Evans and Beddow, (1987) found that viscosity of solder paste increase with increasing the metal content and decrease with increase particle size distribution and temperature. However, not much literature has been found for the study of modification of $\mathrm{wt} \%$ of thinner in order to adjust the viscosity of the paste suitable for screen printing process. The work in this study was divided into several parts; part 1 is the sample preparation of different $w t \%$ of thinner. In this part the viscosity measurement is using the Brookfield viscometer model RV-DV cone and plate with CP-52 spindle. At the same time part 2 is done; preparation of LTCC tape for the whole multilayer substrate process. The results for the part 1 will be used for part 2. After finish part 2, characterization of part 3 will be carry out. Sample analysis and detail discussion is carried out to explain the research findings.

\section{Methodology}

In the following sections, the various process stages will be described. The factors that have the most influence on the quality of the line resolution is the viscosity of the paste.

\subsection{Sample preparation}

Seven samples with different viscosities of the silver paste were used in this process. In this work, a thinner that contains texanol is used to modify the viscosity of commercial LTCC silver paste. The addition of thinner used is varies by its weight percentage from 2, 4, 6, 8, 10 to $12 \%$ of $4 \mathrm{~g}$ silver paste. Table 1 shows a sample description that going to be used for further discussion.

\begin{tabular}{|l|c|c|c|c|c|c|c|}
\hline $\begin{array}{l}\text { Sample } \\
\text { labels }\end{array}$ & S1 & S2 & S3 & S4 & S5 & S6 & S7 \\
\hline $\begin{array}{l}\text { Weight \% of } \\
\text { Thinner }\end{array}$ & 0 & 2 & 4 & 6 & 8 & 10 & 12 \\
\hline
\end{tabular}

Table 1. Samples descriptions of silver conductor paste with varies thinner wt $\%$.

\subsection{Viscosity measurement}

There is some equipment to be used for viscosity measurement which broadly classified into two categories; dynamic and kinematic viscometer. A dynamic viscometer is one of the shear rate can be controlled and measured (rotational viscometer). It is the only type of viscosity measurement that is relevant to fluids where the viscosity is related to the shear rate (non-Newtonian fluids). A kinematic viscometer is where the shear rate can neither be controlled nor measured, for example capillary viscometer. 
For the purpose of this research, brief information about cone and plate geometry viscometer will be given. As noted in Brookfield catalog, cone and plate viscometer offers absolute viscosity determination with precise shear rate and shear stress information. The sample volume is extremely small amount and temperature controlled is easily accomplished. Cone and plate geometry viscometer is particularly advanced rheological analysis of non-Newtonian fluids (Phair \& Kaiser, 2009).

The viscosity measurement was carried out in semi-clean room condition and the ambient temperature is maintained at $25^{\circ} \mathrm{C}$. This is the key factor which might be affects the printing quality. Brookfield viscometer Model RV-DV cone \& plate geometry with CP-52 spindle, using a plate $1.2 \mathrm{~cm}$ radius and a cone angle of $3^{\circ}$ is used. Viscometer speed was set at 0.5 , 1.0, 1.5, 2.0 and 2.5 RPM. The viscosity and torque readings were recorded. Viscosity of the paste for the sample 2, 4, 6, 8, 10 and $12 \mathrm{wt} \%$ of thinner was achieved from the measurement.

\subsection{Multilayer substrate process}

The quality and performance of the paste was evaluated by the screen printing process where the standard thickness is about $15-21 \mu \mathrm{m}$. Screen printing process was carried out for Heraeus tape HL2000 on a KEKO P-200Avf Screen Printer Machine using the TC0306 silver conductor paste from Heraeus. Heraeus HL2000 LTCC is an alumina-based ceramic glass system that has an excellent dielectric properties; the dielectric constant is $7.3 \pm 0.3$ and dielectric loss $(\tan \delta)$ is about 0.0026 . The process was started by printing the test pattern design on the standard LTCC tape dimension $21.4 \mathrm{~cm} \times 21.4 \mathrm{~cm}$.

\begin{tabular}{ll}
\hline Printing parameters & Value \\
\hline Squeegee pressure & $0.1 \mathrm{MPa}$ \\
Squeegee speed & $100 \mathrm{~mm} / \mathrm{s}$ \\
Snap-off & $1.0 \mathrm{~mm}$ \\
\hline
\end{tabular}

Table 2. Printing parameters for printing process of Heraeus HL2000 LTCC tape.

The printing process was also done in a temperature controlled room at $25^{\circ} \mathrm{C}$ and using a standard 325 mesh and angle of $22.5^{\circ}$. The printing parameter used for the process were fixed and controlled to eliminate the variation from the printer (London, 2008). Printing parameter used for the printing process is shown in Table 2.

After the printing, the substrate was dried at $80^{\circ} \mathrm{C}$ for about 20 minutes to remove portion of volatile organic solvent before manual stacking process (see Fig. 2) was carried out to stack the printed tape with 8 "dummy" layers. Drying of the solvents of the conductive paste will reduce the wet thickness volume about $50 \%$. The whole substrate was then laminate using isostatic lamination system ILS-6A at $75^{\circ} \mathrm{C}$ with pressure of $1500 \mathrm{psi}(10 \mathrm{MPa})$ for 10 minutes. The laminated samples were then fired up to $850^{\circ} \mathrm{C}$ by using an LTCC firing profile as suggested by a tape manufacturer.

The effect of the screen printing line resolution was assessed by printing a test pattern design as seen in Fig. 3. The unfired and fired samples were then measured for the line width resolution using an optical microscope OLYMPUS MX40. The line resolution is observed for the horizontal and vertical line. 


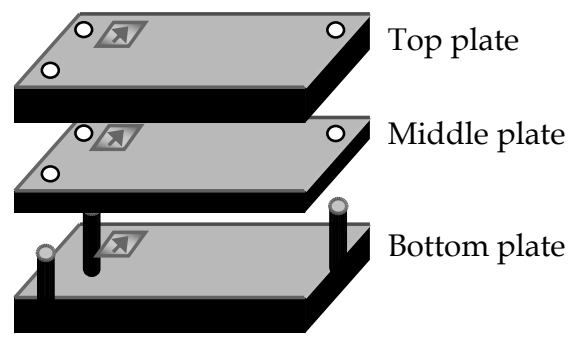

Fig. 2. The manual stacker for collating and stacking process (Alias et al., 2010)

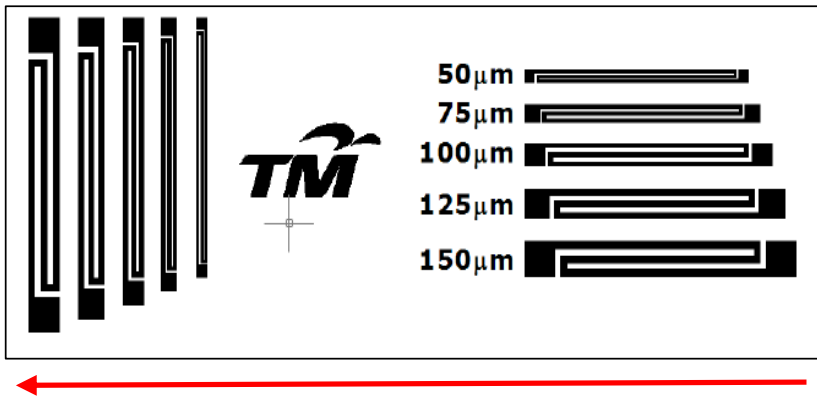

Printing direction

Fig. 3. Printing pattern for the line width evaluation

\subsection{Analysis and measurement}

\subsubsection{Shrinkage and density measurement}

The shrinkage of the Heraeus tape is generally calculated based on equation 1 .

$$
\text { Shrinkage }=\left(\frac{\text { Length }_{\text {beforefired }}-\text { Length }_{\text {after fired }}}{\text { Length }_{\text {before fired }}}\right) \times 100 \%
$$

The properties of the final ceramic composite materials depend on the sintered density of the whole substrate. A stacked and laminated LTCC substrate before firing consists of a relatively porous compact of oxides in combination with a polymer solvent. During sintering the organic solvent evaporates and the oxides react to form crystallites, or grains of the required composition, the grains nucleating at discrete centers and growing outwards until the boundaries meet those of the neighboring crystallites. During this process, the density of the material rises; if this process were to yield perfect crystals meeting at perfect boundaries the density would rise to the theoretical maximum, i.e. the x-ray density, which is the material mass in a perfect unit crystal cell divided by the cell volume. In practice imperfections occur and the sintered mass has microscopic voids both within the grains and at the grain boundaries. The resulting density is referred to as the sintered density. The density of the sample was measured using the Archimedes principle shown in equation (2); 


$$
\rho=\left(\frac{W_{a}}{W_{w}}\right) \rho *_{w}
$$

where $W_{a}=$ weight of sample in air

$\mathrm{W}_{\mathrm{W}}=$ weight of sample in water

$\rho^{*}{ }_{\mathrm{w}}=$ density of water $=1 \mathrm{gcm}^{-3}$

\subsubsection{Monitoring film thickness}

Film thickness need to be carefully controlled and monitored. It is desirable to measure the film thickness at an early stage in the thick film process to reduce error in determination of film thickness for design requirements. For this reason, the thickness of the film should be measured before and after fired. There are some methods to determine the metal thickness using surfometer and non-destructive method. However, in this work we used SEM through cross-section view to measure the film thickness using a FEI NOVA Nano SEM 400 machine. Most of the samples were imaged several times, with at least three pictures in each case, from different areas of the sample holder.

\section{Results and discussion}

\subsection{Viscosity analysis}

The viscosity of thick-film paste is tailored to meet some requirement for screen printing process such as; 1) thixotropic behavior, 2) must have yield point and should have some degrees of hysteresis i.e; the viscosity should be higher with decreasing pressure, as the paste will be on the substrate on the time. Table 3 shows the viscosity for the entire sample for up-curve and down-curve measurement. The paste generally exhibits good shear thinning with a range of viscosity about 7000 to 65000 poise observed at various wt $\%$ of thinner. As seen in the Hereaus data sheet, suitable viscosity value for screen printing process is in the range of $2000-3000$ poise.

Fig. 4 shows the variation of viscosity and shear rate of silver paste with different percentage of thinner. As we can see the trend exhibited by all the samples is generally similar to the work carried out by Bell et al., (1987) and Morissette et al., (2001) on the influence of paste rheology on print morphology and component properties. Sample $0 \%$ to $6 \%$ thinner the viscosity slightly shows decreasing trend. It also obvious that for sample 0 $4 \mathrm{wt} \%$ the trend is slightly overlapped for higher shear rate started from 3.00 to 5.00.

However, the viscosity measured for sample with higher percentage of thinner of $8 \%, 10 \%$ and $12 \%$ did not shows a significant change which could be due to the generation of a liquid-rich layer at the interface between the sample and cone and plate geometry causing a lower viscosity (Durairaj et al., 2009a).

Rheological characterization of the paste is to measure the relationship between shear stress and shear rate varying harmonically with the time, indicating the level of interparticle force or flocculation in the paste. The ideal paste for thick-film films should have a proper degree of pseudoplastic as well as thixotropic behavior (Wu et al., 2010). The thixotropic effect is a result of aggregation of suspended particles. Aggregation in the system caused by the attraction forces such as Van der Waals and repulsion forces due to steric and electrostatic 
effect on the particles. This force prevents the particles from approaching close to each other and create weak physical bond. When the suspension is sheared, this weak force are broken causing the network to break down. A paste with the excellent thixotropic could produce a good printability, help to avoid failure such as incomplete line resolution (Wu et al., 2011; Neidert et al., 2008).

\begin{tabular}{|c|c|c|c|c|c|c|c|}
\hline $\begin{array}{c}\text { Speed } \\
(\mathrm{RPM})\end{array}$ & $\begin{array}{c}0 \% \\
\text { thinner }\end{array}$ & $\begin{array}{c}2 \% \\
\text { thinner }\end{array}$ & $\begin{array}{c}4 \% \\
\text { thinner }\end{array}$ & $\begin{array}{c}6 \% \\
\text { thinner }\end{array}$ & $\begin{array}{c}8 \% \\
\text { thinner }\end{array}$ & $\begin{array}{c}10 \% \\
\text { thinner }\end{array}$ & $\begin{array}{c}12 \% \\
\text { thinner }\end{array}$ \\
\hline \hline 0.5 & 65882 & 64096 & 58540 & 44054 & 25996 & 21035 & 10716 \\
\hline 1 & 54670 & 52884 & 50801 & 37505 & 22622 & 17862 & 8938 \\
\hline 1.5 & 47758 & 47229 & 45707 & 34925 & 21101 & 16801 & 7608 \\
\hline 2 & 42962 & 42962 & 42069 & 32842 & 20042 & 15925 & 7393 \\
\hline 2.5 & 39331 & 39291 & 39251 & 30996 & 19288 & 15399 & 7174 \\
\hline $\begin{array}{c}\text { Speed } \\
(\text { RPM })\end{array}$ & $0 \%$ & $2 \%$ & $4 \%$ & $6 \%$ & $8 \%$ & $10 \%$ & $12 \%$ \\
thinner & thinner & thinner & thinner & thinner & thinner & thinner \\
\hline 2.5 & 39609 & 39331 & 39490 & 31750 & 19526 & 15518 & 7342 \\
\hline \hline 2 & 42863 & 42466 & 42218 & 33536 & 20489 & 16123 & 7640 \\
\hline 1.5 & 47559 & 46369 & 45906 & 35984 & 21696 & 17000 & 8004 \\
\hline 1 & 54869 & 52289 & 50999 & 39192 & 23614 & 18157 & 8434 \\
\hline 0.5 & 68660 & 61913 & 60326 & 45244 & 26988 & 20241 & 9327 \\
\hline
\end{tabular}

Table 3. Viscosity of silver paste with varies thinner weight percentage (in Poise unit)

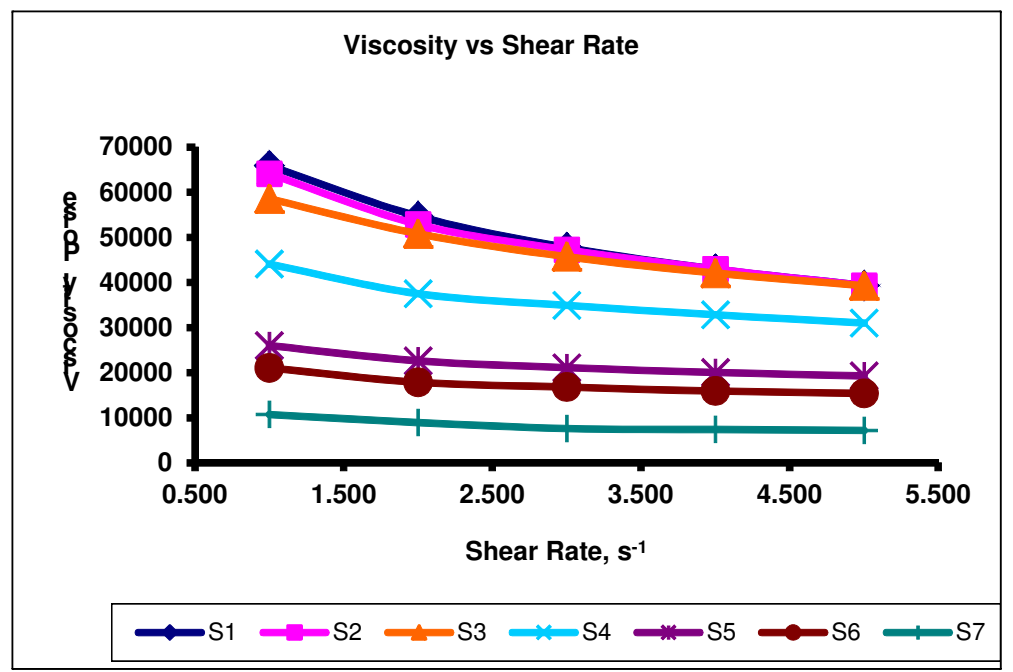

Fig. 4. Viscosity vs. shear rate of silver paste with varies weight $\%$ thinner 


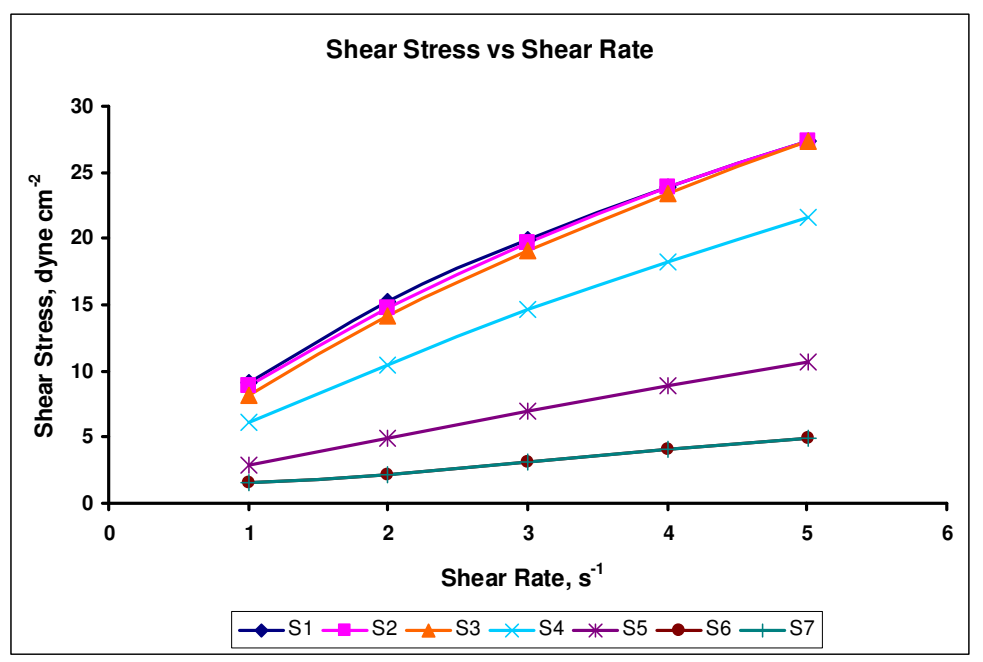

Fig. 5. Shear stress vs shear rate of silver with varies wt $\%$ of thinner

Fig. 5 shows the relation of shear stress and shear rate of silver paste with different wt $\%$ of thinner. The trend of non-Newtonian behavior is consistent with the results found by Chhabra \& Richardson, (1999) for the types of time-independent flow behavior. The timeindependent non-Newtonian fluid behavior observed is pseudoplasticity or shear-thinning characterized by an apparent viscosity which decreases with increasing shear rate. Evidently, these suspensions exhibit both shear-thinning and shear thickening behavior over different range of shear rate and different $w t \%$ of thinner. The viscosity and shear stress relationship with increasing percentage of thinner is plotted in Fig 6. It is clearly observed that both viscosity and shear stress decreases respectively.

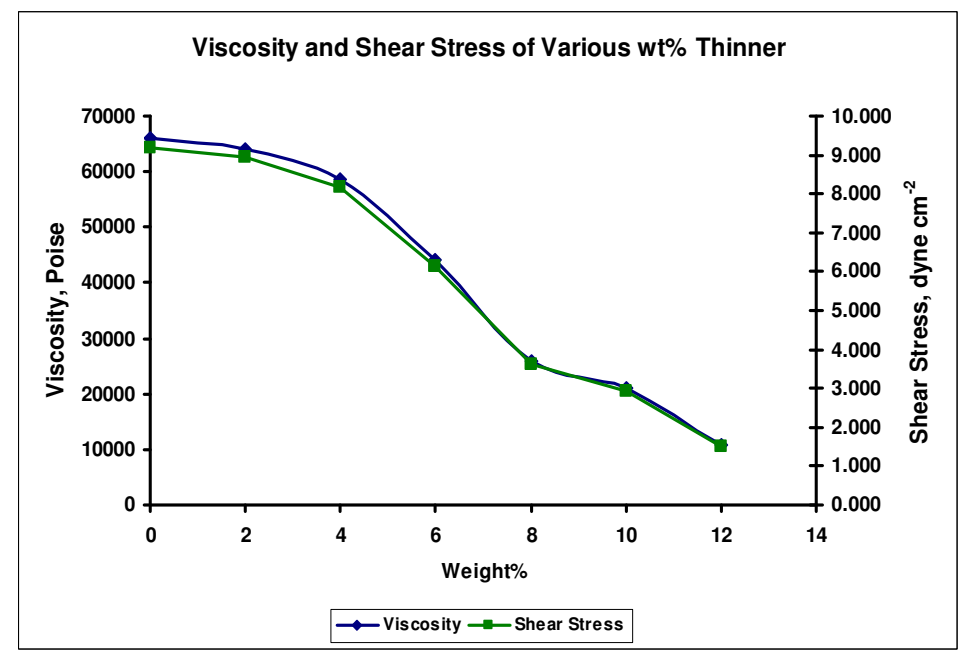

Fig. 6. Viscosity and shear stress of silver paste with varies wt $\%$ of thinner 


\subsection{Effects of weight percentage thinner on the line width resolution}

The relationship of the line width resolution before firing process and after firing process and $w t \%$ of thinner is plotted in Fig. 7. The variation of the line width for $100 \mu \mathrm{m}$ line resolution were found to fluctuate with increasing the wt $\%$ of thinner meaning that it did not shows a significant trend of the line width with increasing the wt \% of thinner. However, due to the optimization of rheology behavior of sample S3 similar to the viscosity of the commercial pastes in the Hereaus data sheets (Hereaus design guideline) so the line width resolution using $4 \%$ thinner (S3) is acceptable compared to the rest wt \% of thinner and it can be used for the printing process.

Fig. 8 shows the relationship between viscosity and shear stress with shear rate of sample S3. As we can see, the viscosity decrease and the shear stress increase as the shear rate increases. The relation of shear rate and shear stress shows that the paste has thixotropic behavior. The plot is similar to the graph by Chhabra \& Richardson, (2008). Through this plot, we can see that not only the values of viscosity are seen to be different but the rate of decrease viscosity with shear rate is also seen to be varied. When shear stress increases the viscosity of the paste with good rheology decrease sharply, paste can flow rapidly through screen (Wang et al., 2002). The similar behavior of this modification paste (S3) with the commercial paste made this sample might be able to be used for fabrication of electrical connection using screen printing process.

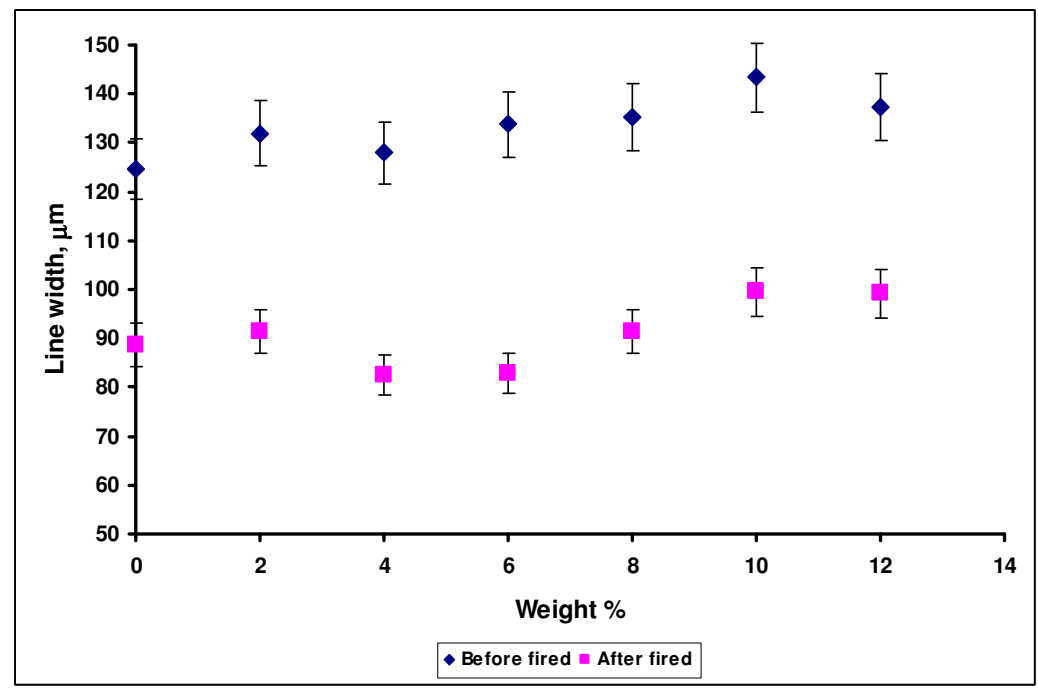

Fig. 7. Printing line width (before and after fired) of silver paste with varies wt $\%$ of thinner

The relation of printed thickness and z-shrinkage with the percentage of thinner is presented in Fig. 9. The thickness of the fired film is about $4 \mu \mathrm{m}$ to $33 \mu \mathrm{m}$ determined via cross section observation using SEM. It is clearly observed that increasing percentage of thinner will cause the printed thickness of the metal conductor on the substrate shows decreasing trend. When the thinner content increase in the paste the viscosity decrease and the films become thinner. It is consistent with the results found by Jabbour et al., (2001), 
where the thickness of the printed pattern depends on the viscosity of the paste. On the other hand, the linear shrinkage for the whole substrate did not show significant increase with increase wt $\%$ of thinner. This shrinkage can be attributed to the solvent loss. Theoretically, the thickness of metal conductor should be constant regardless of the line width since the same mesh is used (Shin et al., 2009). It could be attributed this result to the fact that the edges of the printed line should have a moderate thickness to result in uniform and continuous line width.

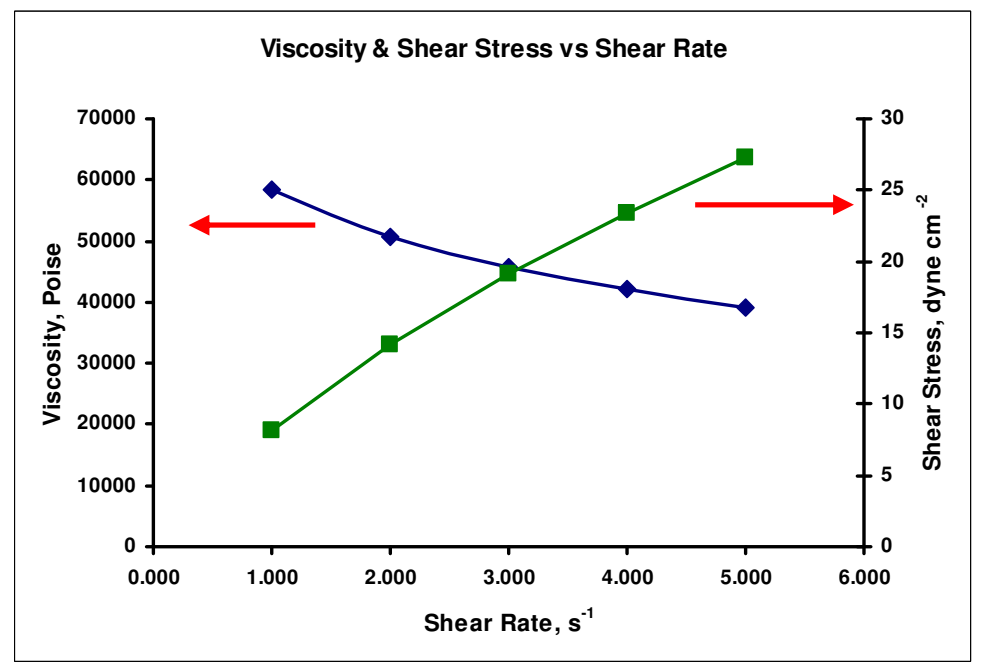

Fig. 8. Viscosity and shear stress as a function of shear rate for silver paste with $4 \mathrm{wt} \%$ of thinner (sample S3)

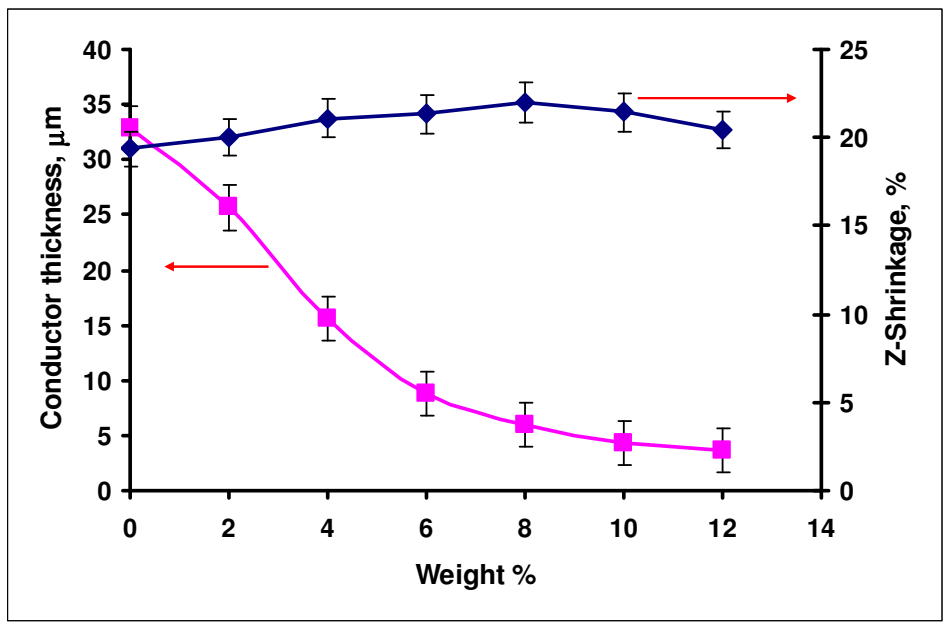

Fig. 9. Influence of printed thickness and shrinkage of silver paste with varies $\mathrm{wt} \%$ of thinner 


\subsection{Printing results - Line resolution}

A series of commercial pastes have been tested for the ability to easily print for various line width and spacing which designed for the horizontal and vertical line at different widths that are $50 \mu \mathrm{m}, 75 \mu \mathrm{m}, 100 \mu \mathrm{m}$ and $125 \mu \mathrm{m}$. The different line width resolution was observed under optical microscope and was found that for sample with zero percentage of thinner (no thinner), the saw-tooth-edge line was observed as shown in Fig. 10. The line resolution is evaluated from the incomplete line and complete line for the required line width. Lines are incomplete and a portion of the lines is missing. The amount of silver seems to be insufficient to form continuous lines. It can be noted here that at lower silver content the edges of the printed lines look spread out with the paste due to its lower viscosity. This might be due to the results of insufficient adhesion of the lines to the LTCC tape. In other way, the line is broken could also be due to the mesh problem. For this study, the screen mesh 325 with the angle of $22.5^{\circ}$ is used. The mesh opening and the viscosity of the paste is not compatible i.e; ink cannot pass through the mesh openings/mesh is unclean. As noted by Pudas et al., (2004) incomplete transfer pattern means the high variations in the printed results.

If it is broken line, then it shows that there are some problems regarding screen printing process (Shapee et al., 2010). It is defined has open defects that are voids on the conductor extending across more than $80 \%$ of the conductor width (Webster, 1975). Print poor resolution means that the printed film does not match the layout in terms of dimensions or shape. It may because of improper rheology or a flaw in the screen (Sergent, 2007). It is obvious that the rheology of the paste is the main factor that affects the poor print resolution. Higher viscosity is better for the good print resolution. The line is considered has a good connectivity when it is no broken line along the line. It also shows that the line resolution for the vertical direction is better than the horizontal direction. Producing optimal screen printed patterns involves consideration of many factors including printer setting, screen options, substrate preparation and paste rheology (Cao et al., 2006). Interaction between these factors must be considered (Dollen \& Barnett, 2005).

If the printed pattern is too thick, the thinner should be added to the paste to adjust the rheology of the paste. As mention by Barlow \& Elshabini, (2007), the thinner is useful to modify the thicker printing provided by the organic binder. The thinner can integrate together with the binder to improve paste characteristics and printing performance. The influence of paste rheology on the line resolution of as printed material has been investigated previously by Wang \& Dougherty, (1994) and Vasudivan \& Zhipping, (2010). As noted by Schwanke \& Polhner, (2008) in their work of fine line printing enhancement, the printed pattern resolution depends on the two factors paste rheology including viscosity, particle size and its thixotropic behavior. The printed pattern for zero wt $\%$ of thinner is too thick. Its create bad surface morphology as seen in Fig. 11 through dielectric layers making it difficult to produce high resolution conductor on subsequent layer (Bender \& Ferreira, 1994). Furthermore, the transferability of the paste and the uniformity of the conductors degraded when the viscosity is too high (Lahti, 2008).

The flow behavior of the paste during the movement of squeegee is an important factor for the screen printing process. During the movement of the squeegee a whirling of the paste happens which leads to a lowering the viscosity and thus, the paste is to be able to pass a screen meshes (Imanaka, 2005). It is believe that increasing wt \% of thinner to the conductor 
paste will cause the viscosity of the paste falls so that it can be push through the mesh opening much more easily compared to the paste without thinner.
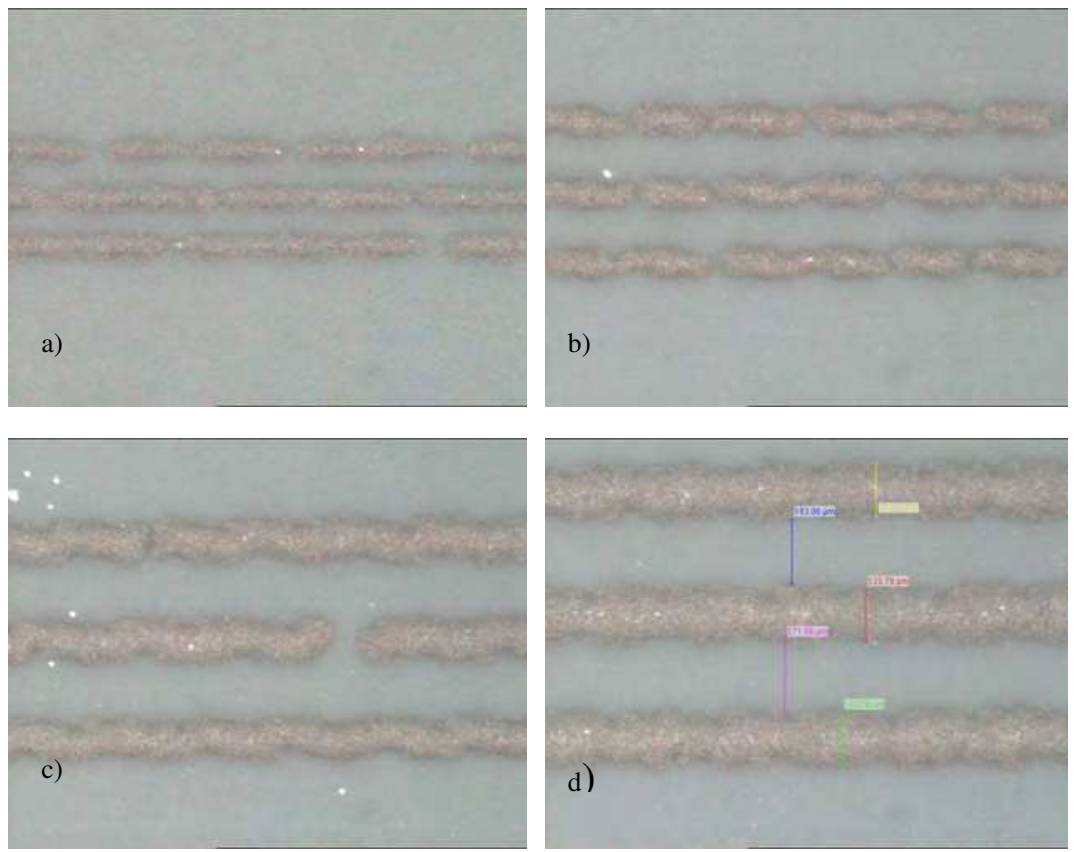

Fig. 10. Line resolution for different width a) $50 \mu \mathrm{m}$, b) $75 \mu \mathrm{m}$, c) $100 \mu \mathrm{m}$ and d) $125 \mu \mathrm{m}$ before firing process

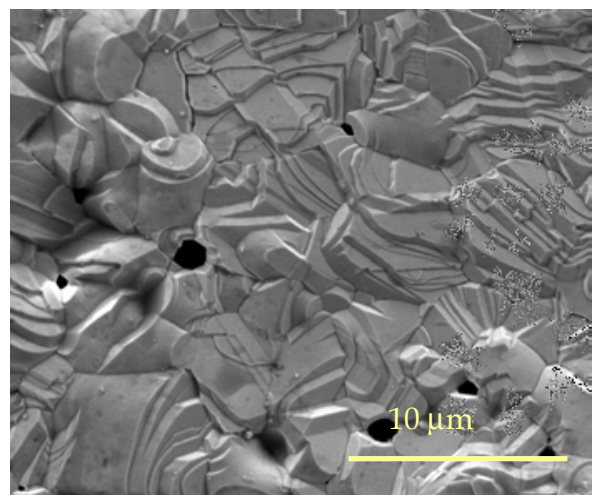

Fig. 11. Surface morphology of conductor paste without thinner

After do some observation, we decide to concentrate on the line width of $100 \mu \mathrm{m}$ to evaluate the quality of the conductor paste with different percentage of thinner for the horizontal and vertical direction. Fig. 12 presents the representative vertical and horizontal lines of $100 \mu \mathrm{m}$ line width for the example of $10 \%$ thinner weight percentage. They were observed at $5 x$ 
magnification. These picture shows that the screen printed line have smooth line edges and consistent line widths. No paste residue were observed between the lines, thus, these line can be used in the interconnection that require long lines (Wang et al., 2005). It also found that the vertical line resolution is better than the horizontal line resolution. It could be due to the mesh angle (Fig. 13) of the screen mesh parallel to printing in direction. This indicates that the smoothness of the edge printing for sample higher wt $\%$ of thinner is not accurate due to the screen wires interfere with the transfer of the viscous paste to the substrate, leaving voids in the printed line.
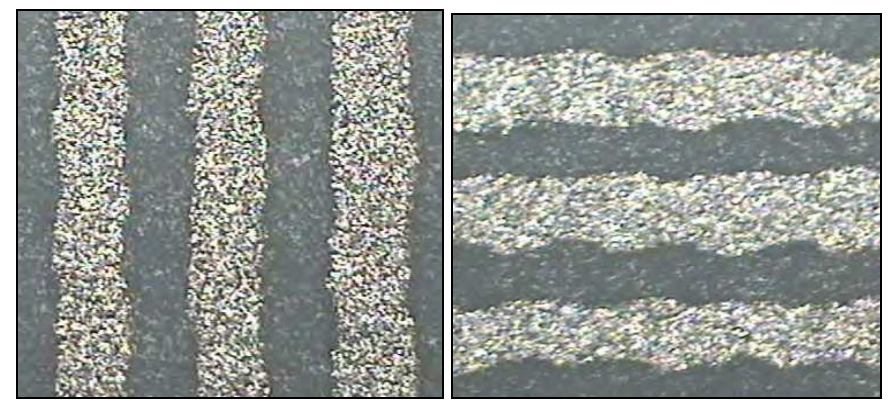

Fig. 12. $100 \mu \mathrm{m}$ line resolution (after fired) for the silver paste with $10 \%$ thinner weight percentage

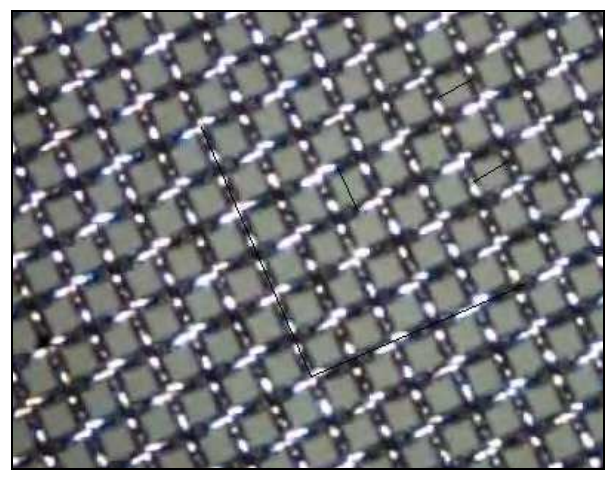

Fig. 13. Screen mesh orientation 325 stainless steel with $22.5^{\circ}$ angles

The effect of screen mesh on printing quality has studied by Stalnecker Jr. (1980) and noted that to get fine line printing the selection of the screen mesh should take into account. The screens for thick film printing should be such that when viscosity and other variables are controlled it should be able to delineate reproducible thickness of the printed line (Dubey, (1974).

\section{Conclusion}

As a conclusion, the viscosity problem can be solved using the different $w \mathrm{t} \%$ of thinner $(2,4,6$, $8,10$ and $12 \mathrm{wt} \%)$. The phenomena observed from screen-printing pastes are also identical to those reported from literature that the viscosity of the paste throughout the screen-printing 
process influences the efficiency of the deposition process and the film's quality. The most higher $w t \%$ of thinner pastes have a lower viscosity than those of others at a low shear rate, while their viscosities at high shear rates, which are directly affects the screen-printing quality, are excessively high, resulting in difficult snap off. The thinner may change the thixotropic of the paste and sometimes can change the paste characteristics. So, by changing the thixotropy of the paste, the printing performance can be better. It may also influence the shape of the printed pattern for the non-linearity of the viscosity versus the shear rate. However, many factors such as filler, resin, the solvent system and the solid content influenced the dispersion degree of particles in the paste, resulting in the different of rheological behaviors. The correlation of the paste rhelogical properties with the pattern transfer efficiency is important to provide better understanding of the effects and the interaction of stainless steel screen mesh process variables to optimize the required printed thickness. Such data will greatly enable the development of more rigorous rheological protocols for the characterization and optimization of the pastes for screen printing in the future.

\section{Acknowledgment}

The authors wish to thank Telekom Malaysia for their funding support under project IMPACT (RDTC/100745) and Assoc. Prof. Dr. Mansor Hashim for the guidance and support for this research work.

\section{References}

Alias, R., Ibrahim, A., Shapee, S.M., Ambak, Z., Yusoff, Z.M. \& Saad, M.R. (2010). Processing Defects Observation of Multilayered Low Temperature Co-fired Ceramic Substrate. Proceedings of International Conference on Electronic Packaging 2010 (ICEP2010), Hokkaido, Japan, May 2010, pp. 300-304.

Amalu, E.H., Ekere, N.N. \& Mallik, S. (2011). Evaluation of Rheological Properties of LeadFree Solder Pastes and their Relationship with Transfer Efficiency During Stencil Printing Process. Materials and Design, Vol. 32, (February 2011), pp. 3189-3197.

Barlow, F.D. \& Elshabini, A. (2007). Ceramic Interconnect Technology Handbook. CRC Press, New York.

Bell Jr., G.C., Rosell, C.M. \& Joslin, S.T. (1987). Rheology of Silver-Filled Glass Die Attach Adhesive for High-Speed Automatic Processing. IEEE Transactions on Components, Hybrids and Manufacturing, Vol. CHMT 12, No. 4, pp. 507-510.

Bender, D.K. and Ferreira, A.M. (1994) Higher Density using Diffusion Pattern Vias and Fine-Line Printing. IEEE Trans. On Comp. ,Pack. And Manufactur Tech. Part A, Vol. 17, No. 3, pp. 485-489.

Brookfield Engineering Labs. Inc. More Solutions to Sticky Problems, in www.BrookfieldEngineering.com.

Burnside, S., Winkel, S., Brooks, K., Shklover, V., Gratzel, M., Hinsch, A., Kinderman, R., Bradbury, C., Hagfeldt, A. \& Pettersson, H. (2000). Deposition and Characterization of Screen-Printed Porous Multi-layer Thick Film Structures from Semiconducting and Conducting Nanomaterials for use in Photovoltaic Devices. Journal of Materials Science: Materials in Electronics, Vol. 11, pp. 355-362. 
Buzby, D. \& Dobie, A. (2008). Fine Line Screen Printing of Thick Film Pastes on Silicon Solar Cells. Proceedings of the $41^{\text {st }}$ International Symposium on Microelectronics (IMAPS 2008), Rhode Island, USA, November 2008.

Cao, K. Cheng, K and Wang, Z. (2006). Optimization of Screen Printing Process. Proceedings of 7 th International Conference on Electronics Packaging Technology, pp. 1-4

Chen, C.-N, Huang, C.-T., Tseng, W.J., \& Wei, M.-H. (2010). Dispersion and Rheology of Surfactant-Mediated Silver Nanoparticle Suspensions. Applied Surface Science, Vol. 257, (July 2010), pp. 650-655.

Chhabra, R.P. \& Richardson, R.F. (1999). Non-Newtonian Flow in the Process Industries: Fundamental and Engineering Applications, Butterworth-Heinemann, Oxford

Chhabra, R.P. \& Richardson, R.F. (2008). Non-Newtonian Flow and Applied Rheology: Engineering Applications, (2nd Ed.), Elsevier Ltd., ISBN 978-0-7506-8532-0, UK.

Chiu, K.-C. (2003). Application of Neural Network on LTCC Fine Line Screen Printing Process. Proc. Of the International Joint Conference on Neural Network. Vol. 2, pp. 10431047.

Dollen, P.V \& Barnett, S. (2005). A Study of Screen Printed Yttria-Stabilized Zirconia Layers for Solid Oxide Fuel Cells. J. Am. Ceram. Soc. Vol. 88, No. 12, pp. 3361-3368.

Dubey, G.C. (1974). Screens for Screen Printing of Electronics Circuits. Microelectronics and Reliability, Vol. 13, pp. 203-207.

Dubey, G.C. (1975). The Squeegee in Printing of Electronics Circuits, Microelectronics and Reliability, Vol. 14, pp. 427-429.

Durairaj, R, Ekere, N.N. and Salam, B. (2004). Thixotropy Flow Behaviour of Solder and Conductive Adhesive Paste. J. Mater. Scie: Mater Electron., Vol. 15, pp. 677-683.

Durairaj, R., Mallik, S., Seman, A. \& Ekere, N.N. (2009a). Investigation of Wall-Slip Effect on Lead-Free Solder Paste and Isotropic Conductive Adhesives. Sadhana, Vol. 34, No.5, (October 2009), pp. 799-810.

Durairaj, R., Ramesh, S., Mallik, S., Seman, A. \& Ekere, N.N. (2009b). Rheological Characterisation and Printing Performance of $\mathrm{Sn} / \mathrm{Ag} / \mathrm{Cu}$ Solder Paste. Materials and Design, Vol. 30, pp. 3812-3818.

Evans J.W. \& Beddow, J.K. (1987). Characterisation of Particle Morphology and Rheological Behaviour in Solder Paste. IEEE Trans. Compo. Hybrids Manufac. Tech., pp. 224-231.

Gao, Y., Kong, X., Munroe, N. and Jones, K. (2010). Evaluation of Silver Paste as a Miniature Direct Methanol Full Cell Electrode. J. of Power Source. Vol. 195, pp. 46-53.

Gilleo, K. (1989). Rheology and Surface Chemistry for Screen Printing. Screen Printing, pp. $128-132$.

Harper, C.A. (2001). Handbook of Ceramic, Glass and Diamond. McGraw Hill, New York.

Heraeus Design Guidelines from www.heraeus.com

Hoornstra, J., Weeber, A.W., Moor, H.H.C. \& Simke, W.C. (1997). The Importance of Paste Rheology in Improving Fine Line, Thick Film Screen Printing of Front Side Metallization, Proceedings of $14^{\text {th }}$ EPSEC, Barcelona, pp. 823-826.

Hwang, S., Lee, S. \& Kim, H. (2009). Sintering Behavior of Silver Conductive Thick Film with Frit in Information Display. J. Electroceram. Vol. 23, pp. 351-355.

Imanaka, Y. (2005). Multilayered Low Temperature Cofired Ceramics (LTCC) Technology, Springer, New York.

Jabbour, G.E., Radspinner, R. \& Peyghambarian, N. (2001). Screen Printing for the Fabrication of Organic-light Emitting Devices. IEEE Journals on selected topics in Quantum Electronics, Vol. 7, No. 5. pp. 769-773. 
Jackson, G.J., Durairaj, R. \& Ekere, N.N. (2002). Characterisation of Lead-Free Solder Pastes for Low-Cost Flip-Chip Bumping. Proceedings of the 27th Annual IEEE/CPMT/SEMI/ International Electronics Manufacturing Technology (IEMT) Symposium, San Jose, CA, USA, July 2002, pp. 223-228.

Jantunen, H., Kangasvieri, T., Vahakangas, J. \& Leppavuori, S. (2003). Design Aspect of Microwave Components with LTCC Techniques, J. of Eur. Ceram. Soc., Vol. 23, pp. 2541-2548.

Kardashian, V.S. \& Vellanki, S.J.R. (1979). A Method for the Rheological Characterization of Thick-Film Paste. IEEE on Components, Hybrids and Manufac. Tech. Vol. CHMT-2, No. 2, pp. 232-239.

Kim, J.W., Lee, Y.-C., Kim, J.-M., Nah, W., Lee, H.-S., Kwon, H.-C. \& Jung, S.-B. (2010). Characterization of Direct Patterned Ag Circuits for RF Applications. Microelectronic Engineering, Vol. 87, pp. 379-382.

Lahti, M. (2008). Gravure Offset Printing for Fabrication of Electronic Devices and Integrated Components in LTCC Modules. PhD Thesis, University Oulu.

Lin, H.-W., Chang, C.-P., Hwu, W.-H. \& Ger, M.-D. (2008). The Rheological Behaviors of Screen Printing Pastes. Journal of Materials Processing Technology, Vol. 197, pp. 284-291.

Lin, J.C., \& Wang, C.Y. (1996). Effects of Surfactant Treatment of Silver Powder on the Rheology of its Thick-Film Paste. Materials Chemistry and Physics, Vol. 45, pp. 136-144.

Lin, Y.-C. and Jean, J.-H. (2004). Constrained Sintering of Silver Circuit Paste. J. Am. Ceram. Soc. Vol. 87 , No. 2, pp. 187-191.

London, D. (2008). Temperature Dependency of Silver Paste with Regards to Print Quality and Electrical Performance of Screen-Printed Solar Cells. Proceedings of the 23rd EU PV Conference, Valencia, Spain, September 2008.

LTCC Production in 2003 KEKO Research Newsletter from www.keko-equipment.com

Mallik, S., Thieme, J., Bauer, R., Ekere, N.N., Seman, A., Bhatti, R. \& Durairaj, R. (2009). Study of the Rheological Behaviours of Sn-Ag-Cu Solder Pastes and their Correlation with Printing Performance. Proceedings of the 11th Electronics Packaging Technology Conference, Singapore, December 2009, pp. 869-874.

Morissette, S.L., Lewis, J.A., Clem, P.G., Cesarano III, J. \& Dimos, D.B. (2001). Direct-Write Fabrication of $\mathrm{Pb}(\mathrm{Nb}, \mathrm{Zr}, \mathrm{Ti}) \mathrm{O} 3$ Devices: Influence of Paste Rheology on Print Morphology and Component Properties. Journal of the American Ceramic Society, Vol. 84, No. 11, pp. 2462-2468.

Neidert, M., Zhang, W., Zhang, D., \& Kipka, A. (2008). Screen-Printing Simulation Study on Solar Cell Front Side Ag Paste, Proceedings of 33rd IEEE Photovoltaic Specialists Conference (PVSC '08), San Diego, CA, USA, May 2008.

Nguty, T.A. \& Ekere, N.N. (2000). Modeling the Effects of Temperature on the Rheology of Solder Pastes and Flux System. Journal of Materials Science: Materials in Electronics, Vol. 11, (July 1999), pp. 39-43.

Parikh, M.R., Quilty Jr., W.F. \& Gardiner, K.M. (1991). SPC and Setup Analysis for Screen Printed Thick Films. IEEE Trans. on Components, Hybrids and Manufacturing Technology, Vol. 14, No. 3, pp. 493-498.

Phair, J.W. \& Kaiser, F.-J. (2009). Determination and Assessment of the Rheological Properties of Pastes for Screen Printing Ceramics, Annual Transactions of the Nordic Rheology Society, Vol. 17, Iceland, August 2009.

Pudas, M., Hagberg, J. \& Leppavuori, S. (2004). Printing Parameters and Ink Components Affecting Ultra-Fine-Line Gravure-Offset Printing for Electronics Applications. J. Europ. Ceram. Soc., Vol. 24, pp. 2943-2950. 
Rane, S.B., Seth, T., Phatak, G.J., Amalnekar, D.P. \& Das, B.K. (2003). Influence of Surfactants Treatment on Silver Powder and its Thick Film. Materials Letters, Vol. 57, pp. 3096-3100.

Rane, S.B., Seth, T., Phatak, G.J., Amalnerkar, D.P. \& Ghatpande, M. (2004). Effect of Inorganic Binders on the Properties of Silver Thick Films. Journal of Materials Science: Materials in Electronics, Vol. 15, pp. 103-106.

Schwanke, D. and Polhner, J. (2008). Enhancement of Fine line Printing Resolution due to Coating of Screen Fabrics. Proceedings of Ceram. Intercon. Microselectronic Tech., pp. 301-308.

Sergent, J.E. (2007). Screen Printing in Ceramic Interconnect Technology Handbook edited by Fred D. Barlow and Aicha Elshabini, CRC Press, pp. 199-233.

Shapee, S.M., Alias, R., Yusoff, M.Z.M., Ibrahim, A., Ambak, Z., \& Saad, M.R. (2010). Screen Printing Resolution of Different Paste Rheology for Printed Multilayer LTCC Tape. Proceedings of International Conference on Electronic Packaging 2010 (ICEP2010), Hokkaido, Japan, May 2010, pp. 255-258.

Shin, D.-Y., Lee. Yongshik. \& Kim, C.H. (2009). Performance Characterization of Screen Printed Radio Frequency Identification Antennas with Silver Nanopaste. Thin Film Solids, pp. 6112-6118.

Shiyong, L., Ning, W, Wencai, X and Yong, L. (2008) Preparation and rheological behavior of lead free silver conducting paste. Materials Chemistry and Physics 111, pp. 20-23.

Stalnecker, Jr., S. G. (1980). Stencils Screens for Fine-Line Printing. Electrocomponent Science and Technology, vol. 7, pp.47-53.

Taylor, B. E., Felten, J. J., Horowitz, S. J., Larry, J.R. and Rosenberg, R. M. (1981). Advances in Low Cost Silver-Containing Thick Film Conductors. Electrocomponent Science and Technology, 1981, Vol. 9, pp. 67-85. Gordon and Breach Science Publishers, Inc. Printed in Great Britain

Vasudivan, S. \& Zhiping, W. (2010). Fine Line Screen Printed Electrodes for Polymer Microfluidics, Proceedings of $12^{\text {th }}$ Electronic Packaging Technology Conference, Singapore, December 2010, pp. 89-93.

Wang, G., Barlow, F. \& Elshabini, A. (2005) Interconnection of Fine Lines to Micro Vias in High Density Multilayer LTCC Substrates. Proc. of International Symposium of Microelectronics.

Wang, S. F. \& Dougherty, J.P. (1994). Silver-Palladium Thick-film conductors. J. Am Ceram. Soc. Vol. 77, No. 12, pp. 3051-3072.

Wang, Y., Zhang, G. and Ma, J. (2002). Research of LTCC/Cu, Ag Multilayer Substratre in Microelectronic Packaging. Materials Science and Engineering B, Vol. 94. pp. 48-53.

Webster, R. (1975). Fine Line Screen Printing Yields as a Function of Physical Design Parameters. IEEE Trans. On Manufac. Tech. Vol. MFT-4, No. 1, pp. 14-20.

Wu, S.P., Zhao, Q.Y., Zheng, L.Q \& Ding, X. H. (2011). Behaviors of ZnO-doped silver thickfilm and silver grain growth mechanism. Solid States Science, Vol. 13, pp. 548-552.

Wu, S.P., Zheng, L.Q., Zhao, Q.Y. and Ding, X. H. (2010). Preparation and characterization of high-temperature silver thick film and its application in multilayer chip inductances. Colloids and Surface A: Physicochemical and engineering aspects, Vol. 372, pp. 120-126.

Yin, W., Lee, D.-H., Choi, J., Park, C. \& Cho, S.M. (2008). Screen Printing of Silver Nanoparticle Suspension for Metal Interconnects. Korean Journal of Chemistry Engineering, Vol. 25, No. 6, (April 2008), pp. 1358-1361. 


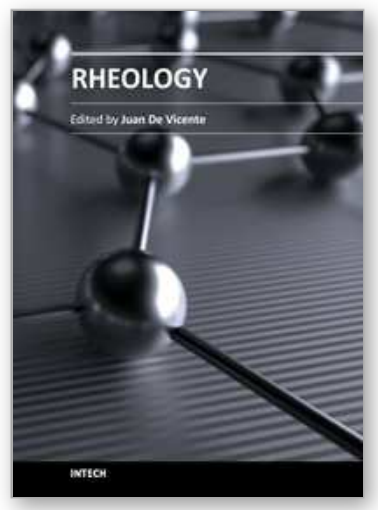

\author{
Rheology \\ Edited by Dr. Juan De Vicente
}

ISBN 978-953-51-0187-1

Hard cover, 350 pages

Publisher InTech

Published online 07, March, 2012

Published in print edition March, 2012

This book contains a wealth of useful information on current rheology research. By covering a broad variety of rheology-related topics, this e-book is addressed to a wide spectrum of academic and applied researchers and scientists but it could also prove useful to industry specialists. The subject areas include, polymer gels, food rheology, drilling fluids and liquid crystals among others.

\title{
How to reference
}

In order to correctly reference this scholarly work, feel free to copy and paste the following:

Rosidah Alias and Sabrina Mohd Shapee (2012). Rheological Behaviors and Their Correlation with Printing Performance of Silver Paste for LTCC Tape, Rheology, Dr. Juan De Vicente (Ed.), ISBN: 978-953-51-0187-1, InTech, Available from: http://www.intechopen.com/books/rheology/rheological-behaviors-and-theircorrelation-with-printing-performance-of-silver-paste-for-ltcc-tape

\section{INTECH}

open science | open minds

\section{InTech Europe}

University Campus STeP Ri

Slavka Krautzeka 83/A

51000 Rijeka, Croatia

Phone: +385 (51) 770447

Fax: +385 (51) 686166

www.intechopen.com

\section{InTech China}

Unit 405, Office Block, Hotel Equatorial Shanghai

No.65, Yan An Road (West), Shanghai, 200040, China

中国上海市延安西路65号上海国际贵都大饭店办公楼405单元

Phone: +86-21-62489820

Fax: $+86-21-62489821$ 
(C) 2012 The Author(s). Licensee IntechOpen. This is an open access article distributed under the terms of the Creative Commons Attribution 3.0 License, which permits unrestricted use, distribution, and reproduction in any medium, provided the original work is properly cited. 